\title{
MEASURING EFFICIENCY OF FOOTBALL TEAMS BY MULTI-STAGE DEA MODEL
}

\author{
Dijana Petrović Djordjević, Mirko Vujošević, Milan Martić
}

Original scientific paper

Using the nonparametric variable output-oriented DEA (Data Envelopment Analysis) model, this paper analyses technical efficiency of the observed national football team in the qualifications for 2010 FIFA World Cup. If DEA model has a two stage structure, the first stage uses inputs to generate outputs that then became the inputs to the second stage. The indexes of efficiency, previously generated for attack and defence, will be implemented as parameters in the second-stage DEA analysis in accordance with the initial aim of this paper, to present new results as the outcome of the comprehensive approach to both inseparable aspects of the football. This theoretical approach is structured as follows: the football teams are defined as DMU (DecisionMaking Units), then, the methodology is established, specifically, the stages of range and objectives, analysis of procedure and variables, and the description of the theoretical analysis used.

Keywords: data envelopment analysis; decision-making units; efficiency; function of sports production

Mjerenje učinkovitosti nogometnih timova primjenom višestupanjskog DEA modela

Izvorni znanstveni članak

Primjenom neparametarskog izlazno orijentiranog varijabilnog DEA modela, u članku je dana analiza tehničke učinkovitosti promatrane nogometne reprezentacije tijekom kvalifikacijskog ciklusa za Svjetsko prvenstvo 2010. Ako metoda obavijanja podataka posjeduje dvostupanjsku strukturu, prvi stupanj koristi ulaze u generiranju izlaza koji su ulazi drugog stupnja. Ranije generirani indeksi učinkovitosti za aspekt napada i obrane naći će se u ulozi novih parametara u drugostupanjskoj DEA analizi koja za cilj ima prikazati nove rezultate kao posljedicu integralnog promatranja oba i suštinski neodvojiva aspekta nogometne igre. Ovaj teorijski prilaz je strukturiran na sljedeći način: nogometni timovi su definirani kao produkcijske jedinice o kojima se odlučuje, zatim je utvrđena metodologija, specifično, opseg promjena i kriteriji, procedura analize i varijable, kao i opis korištene teorijske analize.

Ključne riječi: metoda obavijanja podataka; organizaciona jedinica za odlučivanje; sportska produkcijska funkcija; učinkovitost

\section{Introduction}

Initial idea on application of production function [1] in sports economy (baseball league) defines output as a product of arithmetic means of income and number of visitors in the function of players' technical skills and number of players, as first input variable and second input variable which is represented by qualities of coach, standard of football field, technical skills of opponent team and transport. Later on, Scully [2] has done the first estimation of production function, again for baseball league, but unlike previous approach, monetary effect and operating efficiency represent the model's outputs. In other words, the first equation of the model defines income which is determined by the percentage of wins and geographic size of a market and the second one defines team's result whereas the percentage of wins is determined by aggregation of "hitter and pitcher". Relation between individual results of players, as input, and team's results, as output, is standardised specification of production function, and the idea has been extended for estimation of team efficiency in various sports disciplines: basketball [3, 4], rugby [5] and for the first time - English Premier League [6]. Contribution of these papers, published in journals dedicated only to economic issues, is in the first instance reflected in substitution of parametric techniques of assessment of production functions with nonparametric techniques of assessment, especially in application of DEA modelling [7].

Production activity, as a basic characteristic of football game, implies affiliation of football process to the set of production processes, which then can evidently be modelled, in football industry, with production function. For the past ten years, DEA applications in sports economics have been focused on issues of individual efficiency (for example, statistics of running in professional baseball) or they have been dealing with professional football in Europe, from institutional point of view, and therefore enlarged application in football (for the past few years) at the level of a team $[8 \div 15]$ should show to technically oriented football professionals (and the media representatives) factors which determine efficiency and effectiveness, consistency of results, different combinations of input and output, degree of correlation between efficiency and effectiveness and position, for example, in final classification.

The paper is organized as follows. After the first, introductory part, the second part of the paper shows basis of DEA modelling and selected model from the set of DEA models. Then, tabular presentations show values of efficiency indices of offense and defense, obtained in separate analysis, which had output role in the second application of DEA method. By application of EMS (Efficiency Measurement System) software, the third part of the paper will essentially result in new conclusions in efficiency analysis of the observed national team during the qualifications for 2010 FIFA World Cup, derived from the initial assumptions that include comprehensive aspect of offense and defence. Finally, summary and discussion are presented in conclusion part.

\section{DEA models in analysis of football: Methodological aspects}

DEA models should be able to consider real football values and to identify "weaknesses" of a football team, with respect to tactics of its offense and defence. For example, in the first phase, player's talent can be used for two outputs, one positive (scored goals) and the other negative (received goals), which should be minimized, 
and this is what independently determines efficiency of offense and efficiency of defence of a football team.

That is, variables of the first phase are input indicators of offense and defence capabilities, the signs of which can be positive and negative, leading to an estimate of efficient offense production limit, independently from the one for defence.

From the perspective of offense, possession of ball and its movement through passes, dribbling, hits on goal, etc., represents active actions of creating of the chances for scoring goals. Statistically, offenses, passes in penalty area and hits towards goal define offensive actions of a football team. For example, these three variables can be input variables containing relative significance of time during which a team possesses the ball, showing the level of team's offense.

Defensive actions of players are observed as taking away the ball from opponent team in order to, for example, perform new offense. These actions mean interception and prevention of opponent team from scoring goals, and therefore statistics of repossessing ball and goal-keeper's action are clear indicators of stated activities. Inputs can (but don't have to) be presented relatively, for example by time during which opponent team possesses ball, showing the level of team's defence.

Decomposition of analysis, output variables which facilitate triumph of a team, can be defined independently, as positive outputs and reverse negative outputs (for example, instead of result being defined in percentage of wins). Measurement of used outputs combines offense productivity (scoring goals), with defence efficiency (preventing opponent from scoring), and therefore scored goals (number of goals) and reverse number of received goals (own goals count as goals scored by opponent team) during cycle of a competition, can be used as outputs.

Indicated variables of the second phase are both indicators of technical efficiency of offense and defence, estimated in the previous phase, while the output classification achieved by a football team - is based on cumulative result obtained in each match individually. This analysis estimates importance of applied tactics offense, defence or combination thereof - which characterize teams depending on the final results achieved during a competition cycle.

\section{Technical efficiency measurement of the national football team in qualification matches for 2010 FIFAWC}

Analysis of efficiency of the national team which participated in qualification cycle for 2010 FIFA World Cup South Africa and which was successfully classified for final tournament is based on technical aspects of sports. Research will show whether the analysis of technical efficiency is of any help when it comes to explanation of performances of sport in this national team for the period that includes total of 17 matches, out of which 10 were part of qualification cycle, and 7 of them were friendly. Out of total number of games, national team in focus of this analysis $(\operatorname{TEAM}(*))$ hosted 8 , and in the remaining 9 played as a guest. The matches of the $\operatorname{TEAM}(*)$ were played with national teams of the other countries, 5 of 12 participating in the same qualyfing group: $\operatorname{TEAM}(1), \operatorname{TEAM}(2), \operatorname{TEAM}(6), \quad \operatorname{TEAM}(7)$,
$\operatorname{TEAM}(8)$ and $\operatorname{TEAM}(3), \quad \operatorname{TEAM}(4), \quad \operatorname{TEAM}(5)$, TEAM(9), TEAM(10), TEAM(11), TEAM(12) which represent national teams of the countries national teams of countries selected as opponents in friendly matches that have significance in the tactical-technical preparation of the TEAM $\left(^{*}\right)$ for the main event. Indexing opponents was conducted in accordance with the matches' chronology.

Integration of DEA modelling and football in this case was facilitated by conclusion of agreement between The National Football Association to which it belongs TEAM(*) and Sport Universal Process SAS (SUP). SUP has developed global information system called AMISCO intended for assistance in management and professional sports sector. AMISCO measures correct positions of all players in the field during the entire game. Measures of players' positions and movements enable generating of 2D animation of a game, together with tactical and sports information on individual and team performance of players. SUP has developed additional software for analysis (Video Pro) which facilitates full tactical analysis of football game by including each contact of a player with ball and direct approach to digitally synchronised tactic analysis of both team and players. Therefore, data used in this paper (provided by Sport Universal thanks to copyright software for analysis of football games AMISCO, which represents leading programme for applied statistics in football), are based on detailed statistical analysis of technical and tactical elements of a game, according to records made by specific cameras which cover the entire field and overall activity of all players, regardless of ball position. Only a small subset of data included in this large database will be used in further analysis.

In accordance with the restrictions relating to the ownership of the data used in this analysis, publicly naming organizations and national teams is avoided, but the interested reader can get more details by contacting the authors.

\subsection{Numerical values: Empirical results for the determination of technical efficiency}

In football, the only production factor is a team with players, and therefore it is necessary to select such indicators which will precisely measure players' skills.

Football, during its development, has been improved through segments. Technical elements are considered one of the most important segments of a football game. Evolution of technical elements has developed new requirements for football game and football tactics. If some elements and sub-elements of football technique were thoroughly analysed, they would result in unambiguous conclusion that all of them are, in the end, some sort of tactics. In other words, technical element, alone or in combination with other elements, facilitates the development of targeted combinations representing a tactical idea.

For this reason, the following input and output variables have been selected as potentially important for achievement of results.

Input variables:

- Total number of crosses $(N C)$,

- Number of successful crosses $(N s C)$, 
- Total number of crosses in play $(N C P)$,

- Number of successful long through balls in play $(\mathrm{NsCP})$,

- Total number of passes in play (passing of a ball) $(N P P)$,

- Number of successful passes in play $(N s P P)$,

- Number of shots (NS),

- Number of shots on target (NST),

- Total number of fouls made $(N F m)$,

- Total number of air duels $(N A D)$,
- $\quad$ Number of won air duels $(N A D w)$,

- Total number of ground duels $(N G D)$,

- Number of won ground duels $(N G D w)$,

- Number of successful dribbling $(N s D)$.

Output variables:

- Total number of recognized scored goals $(N G)$.

Tab. 1 and Tab. 2 show data on identified factors.

Table 1 Data for TEAM $(*)$ for the offense on the matches at home and away

\begin{tabular}{|c|c|c|c|c|c|c|c|c|c|c|c|c|c|c|c|}
\hline Match & $N G$ & $N C$ & $\mathrm{NsC}$ & $N C P$ & $\mathrm{NsCP}$ & $N P P$ & $N s P P$ & $N S$ & $N S T$ & $\mathrm{NFm}$ & NAD & $N A D w$ & $N G D$ & $N G D w$ & $N s D$ \\
\hline TEAM(*)vsTEAM(1) & 2 & 51 & 10 & 45 & 9 & 545 & 493 & 19 & 9 & 19 & 30 & 21 & 42 & 19 & 9 \\
\hline TEAM $(*)$ vsTEAM(2) & 3 & 31 & 9 & 23 & 4 & 398 & 326 & 14 & 6 & 27 & 36 & 19 & 43 & 25 & 12 \\
\hline TEAM(*)vsTEAM(3) & 6 & 22 & 10 & 16 & 9 & 349 & 291 & 20 & 11 & 27 & 31 & 21 & 29 & 16 & 8 \\
\hline TEAM(*)vsTEAM(4) & 0 & 14 & 2 & 13 & 2 & 351 & 278 & 17 & 5 & 23 & 53 & 33 & 52 & 21 & 7 \\
\hline TEAM(*)vsTEAM(5) & 2 & 39 & 8 & 25 & 8 & 336 & 266 & 13 & 5 & 20 & 48 & 33 & 37 & 18 & 5 \\
\hline TEAM(*)vsTEAM(6) & 1 & 14 & 6 & 9 & 3 & 277 & 213 & 12 & 5 & 21 & 39 & 15 & 33 & 17 & 7 \\
\hline TEAM(*)vsTEAM(7) & 1 & 19 & 4 & 14 & 2 & 346 & 278 & 15 & 4 & 21 & 48 & 32 & 26 & 14 & 7 \\
\hline TEAM(*)vsTEAM(8) & 5 & 33 & 13 & 23 & 8 & 280 & 222 & 27 & 9 & 33 & 40 & 26 & 24 & 12 & 9 \\
\hline TEAM(7)vsTEAM(*) & 1 & 20 & 9 & 15 & 6 & 344 & 275 & 7 & 1 & 18 & 32 & 16 & 55 & 27 & 5 \\
\hline TEAM(6)vsTEAM(*) & 3 & 11 & 2 & 9 & 2 & 351 & 295 & 7 & 5 & 27 & 36 & 17 & 30 & 11 & 13 \\
\hline TEAM(9)vsTEAM(*) & 2 & 25 & 9 & 18 & 8 & 471 & 380 & 17 & 7 & 23 & 28 & 20 & 39 & 21 & 10 \\
\hline TEAM(8)vsTEAM(*) & 3 & 17 & 3 & 12 & 2 & 265 & 166 & 8 & 3 & 21 & 40 & 22 & 15 & 7 & 2 \\
\hline TEAM(1)vsTEAM(*) & 2 & 44 & 8 & 37 & 8 & 569 & 512 & 21 & 10 & 19 & 36 & 23 & 38 & 18 & 7 \\
\hline TEAM(10)vsTEAM(*) & 3 & 18 & 7 & 16 & 6 & 435 & 350 & 7 & 4 & 16 & 26 & 14 & 18 & 12 & 0 \\
\hline TEAM(2)vsTEAM(*) & 1 & 25 & 10 & 13 & 7 & 294 & 182 & 16 & 6 & 19 & 37 & 20 & 31 & 17 & 10 \\
\hline TEAM(11)vsTEAM(*) & 1 & 25 & 7 & 19 & 4 & 530 & 458 & 18 & 6 & 17 & 35 & 21 & 20 & 12 & 7 \\
\hline TEAM(12)vsTEAM(*) & 1 & 13 & 4 & 18 & 2 & 383 & 320 & 11 & 5 & 21 & 29 & 16 & 20 & 13 & 7 \\
\hline
\end{tabular}

Table 2 Data for TEAM (*) for the defense on the matches at home and away

\begin{tabular}{|c|c|c|c|c|c|c|c|c|c|c|c|c|c|c|c|}
\hline Match & $N G$ & $N C$ & $\mathrm{NsC}$ & $N C P$ & $\mathrm{NsCP}$ & $N P P$ & $N S P P$ & $N S$ & NST & $N F m$ & $N A D$ & $N A D w$ & $N G D$ & $N G D w$ & $N s D$ \\
\hline TEAM(*)vsTEAM(1) & 0 & 5 & 1 & 3 & 0 & 188 & 137 & 4 & 0 & 16 & 30 & 9 & 42 & 23 & 5 \\
\hline TEAM(*)vsTEAM(2) & 0 & 25 & 4 & 18 & 2 & 363 & 285 & 8 & 2 & 19 & 36 & 17 & 43 & 18 & 4 \\
\hline TEAM(*)vsTEAM(3) & 1 & 23 & 6 & 16 & 3 & 414 & 347 & 18 & 10 & 21 & 31 & 10 & 29 & 13 & 6 \\
\hline TEAM(*)vsTEAM(4) & 1 & 14 & 2 & 13 & 2 & 321 & 247 & 8 & 4 & 33 & 53 & 20 & 52 & 31 & 2 \\
\hline TEAM(*)vsTEAM(5) & 0 & 39 & 8 & 25 & 7 & 299 & 224 & 15 & 4 & 21 & 48 & 15 & 37 & 19 & 5 \\
\hline TEAM(*)vsTEAM(6) & 0 & 26 & 6 & 17 & 4 & 326 & 248 & 15 & 2 & 30 & 39 & 24 & 33 & 16 & 4 \\
\hline TEAM(*)vsTEAM(7) & 1 & 21 & 1 & 15 & 1 & 357 & 298 & 15 & 4 & 12 & 48 & 16 & 26 & 12 & 17 \\
\hline TEAM(*)vsTEAM $(8)$ & 0 & 16 & 6 & 14 & 4 & 264 & 202 & 14 & 1 & 33 & 40 & 14 & 24 & 12 & 6 \\
\hline TEAM(7)vsTEAM(*) & 2 & 24 & 7 & 17 & 6 & 519 & 454 & 23 & 10 & 19 & 32 & 16 & 55 & 28 & 14 \\
\hline TEAM(6)vsTEAM(*) & 1 & 44 & 7 & 36 & 5 & 401 & 329 & 10 & 2 & 30 & 36 & 19 & 30 & 19 & 8 \\
\hline TEAM(9)vsTEAM(*) & 0 & 15 & 4 & 11 & 3 & 344 & 262 & 9 & 4 & 18 & 28 & 8 & 39 & 18 & 1 \\
\hline TEAM(8)vsTEAM(*) & 2 & 34 & 10 & 27 & 9 & 424 & 311 & 14 & 4 & 30 & 40 & 18 & 15 & 8 & 8 \\
\hline TEAM(1)vsTEAM(*) & 0 & 12 & 3 & 9 & 3 & 190 & 141 & 9 & 3 & 18 & 36 & 13 & 38 & 20 & 6 \\
\hline TEAM(10)vsTEAM $(*)$ & 1 & 27 & 5 & 18 & 2 & 482 & 397 & 12 & 8 & 9 & 26 & 12 & 18 & 6 & 0 \\
\hline TEAM(2)vsTEAM(*) & 2 & 21 & 4 & 13 & 1 & 259 & 141 & 19 & 12 & 18 & 37 & 17 & 31 & 14 & 4 \\
\hline TEAM(11)vsTEAM(*) & 0 & 27 & 7 & 19 & 3 & 383 & 310 & 13 & 2 & 20 & 35 & 14 & 20 & 8 & 2 \\
\hline TEAM(12)vsTEAM(*) & 0 & 23 & 5 & 18 & 2 & 409 & 328 & 11 & 6 & 28 & 29 & 13 & 20 & 7 & 9 \\
\hline
\end{tabular}

Except for previously stated observations, our selection of inputs for offense and defence is also based on analysis of correlation between inputs and an output variable. The selected inputs show positive correlations (generally of statistical importance) with relevant output. When it comes to defence, the idea is similar, even though additional assumptions should be introduced. In this case, events in the game achieved by opponent team will be taken as defensive inputs instead of defensive actions of a team that has been analysed. Therefore, meaning of defence efficiency can be expressed as capability to receive fewer goals with more chances of opponent team.

\subsection{Numerical values: Reduction of model dimensions}

In the first stage of problem observation, it may be concluded that it is impossible to keep all identified input variables due to incompliance with instructions for definition of appropriate DEA model. Having in mind that 14 input variables and one output variable have been identified, with 17 decision making units, it is clear that some reductions have to be done.

\subsubsection{Reduction of inputs by compression of similar variables}

The first suggested reduction of input dimension refers to introduction of new parameters which will represent effect of a team through relation of successful and total values of the same kind, in compliance with Tabs. 3 and 4 .

New variables have been introduced:

- Effect of successful ones out of total crosses $(C)$,

- Effect of successful ones out of total crosses in play $(C P)$, 
- Effect of successful ones out of total passes in play $(P P)$,

- Effect of successful ones out of total number of air duels $(A D)$,

- Effect of successful ones out of total number of ground duels $(G D)$.
By application of this step, we have reduced number of inputs from 14 to 9 . However, it is necessary to carry out additional reductions.

Table 3 Data for TEAM $(*)$ for the offense on the matches at home and away - reduction

\begin{tabular}{|c|c|c|c|c|c|c|c|c|c|c|}
\hline Match & $N G$ & $C$ & $C P$ & $P P$ & $N S$ & $N S T$ & $N F m$ & $A D$ & $G D$ & $N s D$ \\
\hline TEAM(*)vsTEAM(1) & 2 & 19,61 & 20,00 & 90,46 & 19 & 9 & 19 & 70,00 & 45,24 & 9 \\
\hline TEAM(*)vsTEAM(2) & 3 & 29,03 & 17,39 & 81,91 & 14 & 6 & 27 & 52,78 & 58,14 & 12 \\
\hline TEAM(*)vsTEAM(3) & 6 & 45,45 & 56,25 & 83,38 & 20 & 11 & 27 & 67,74 & 55,17 & 8 \\
\hline TEAM(*)vsTEAM(4) & 0 & 14,29 & 15,38 & 79,20 & 17 & 5 & 23 & 62,26 & 40,38 & 7 \\
\hline TEAM(*)vsTEAM(5) & 2 & 20,51 & 32,00 & 79,17 & 13 & 5 & 20 & 68,75 & 48,65 & 5 \\
\hline TEAM(*)vsTEAM(6) & 1 & 42,86 & 33,33 & 76,90 & 12 & 5 & 21 & 38,46 & 51,52 & 7 \\
\hline TEAM(*)vsTEAM(7) & 1 & 21,05 & 14,29 & 80,35 & 15 & 4 & 21 & 66,67 & 53,85 & 7 \\
\hline TEAM(*)vsTEAM(8) & 5 & 39,39 & 34,78 & 79,29 & 27 & 9 & 33 & 65,00 & 50,00 & 9 \\
\hline TEAM(7)vsTEAM(*) & 1 & 45,00 & 40,00 & 79,94 & 7 & 1 & 18 & 50,00 & 49,09 & 5 \\
\hline TEAM(6)vsTEAM(*) & 3 & 18,18 & 22,22 & 84,05 & 7 & 5 & 27 & 47,22 & 36,67 & 13 \\
\hline TEAM(9)vsTEAM(*) & 2 & 36,00 & 44,44 & 80,68 & 17 & 7 & 23 & 71,43 & 53,85 & 10 \\
\hline TEAM(8)vsTEAM(*) & 3 & 17,65 & 16,67 & 62,64 & 8 & 3 & 21 & 55,00 & 46,67 & 2 \\
\hline TEAM(1)vsTEAM(*) & 2 & 18,18 & 21,62 & 89,98 & 21 & 10 & 19 & 63,89 & 47,37 & 7 \\
\hline TEAM(10)vsTEAM(*) & 3 & 38,89 & 37,50 & 80,46 & 7 & 4 & 16 & 53,85 & 66,67 & 0 \\
\hline TEAM(2)vsTEAM(*) & 1 & 40,00 & 53,85 & 61,90 & 16 & 6 & 19 & 54,05 & 54,84 & 10 \\
\hline TEAM(11)vsTEAM(*) & 1 & 28,00 & 21,05 & 86,42 & 18 & 6 & 17 & 60,00 & 60,00 & 7 \\
\hline TEAM(12)vsTEAM(*) & 1 & 30,77 & 11,11 & 83,55 & 11 & 5 & 21 & 55,17 & 65,00 & 7 \\
\hline
\end{tabular}

Table 4 Data for TEAM $\left(^{*}\right)$ for the defense on the matches at home and away - reduction

\begin{tabular}{|c|c|c|c|c|c|c|c|c|c|c|}
\hline Match & $N G$ & $C$ & $C P$ & $P P$ & $N S$ & $N S T$ & $N F m$ & $A D$ & $G D$ & $N s D$ \\
\hline TEAM(*)vsTEAM(1) & 0 & 20,00 & 0,00 & 72,87 & 4 & 0 & 16 & 30,00 & 54,76 & 5 \\
\hline TEAM(*)vsTEAM(2) & 0 & 16,00 & 11,11 & 78,51 & 8 & 2 & 19 & 47,22 & 41,86 & 4 \\
\hline TEAM(*)vsTEAM(3) & 1 & 26,09 & 18,75 & 83,82 & 18 & 10 & 21 & 32,26 & 44,83 & 6 \\
\hline TEAM(*)vsTEAM(4) & 1 & 14,29 & 15,38 & 76,95 & 8 & 4 & 33 & 37,74 & 59,62 & 2 \\
\hline TEAM(*)vsTEAM(5) & 0 & 20,51 & 28,00 & 74,92 & 15 & 4 & 21 & 31,25 & 51,35 & 5 \\
\hline TEAM(*)vsTEAM(6) & 0 & 23,08 & 23,53 & 76,07 & 15 & 2 & 30 & 61,54 & 48,48 & 4 \\
\hline TEAM(*)vsTEAM(7) & 1 & 4,76 & 6,67 & 83,47 & 15 & 4 & 12 & 33,33 & 46,15 & 17 \\
\hline TEAM(*)vsTEAM(8) & 0 & 37,50 & 28,57 & 76,52 & 14 & 1 & 33 & 35,00 & 50,00 & 6 \\
\hline TEAM(7)vsTEAM(*) & 2 & 29,17 & 35,29 & 87,48 & 23 & 10 & 19 & 50,00 & 50,91 & 14 \\
\hline TEAM(6)vsTEAM(*) & 1 & 15,91 & 13,89 & 82,04 & 10 & 2 & 30 & 52,78 & 63,33 & 8 \\
\hline TEAM(9)vsTEAM(*) & 0 & 26,67 & 27,27 & 76,16 & 9 & 4 & 18 & 28,57 & 46,15 & 1 \\
\hline TEAM(8)vsTEAM(*) & 2 & 29,41 & 33,33 & 73,35 & 14 & 4 & 30 & 45,00 & 53,33 & 8 \\
\hline TEAM(1)vsTEAM(*) & 0 & 25,00 & 33,33 & 74,21 & 9 & 3 & 18 & 36,11 & 52,63 & 6 \\
\hline TEAM(10)vsTEAM(*) & 1 & 18,52 & 11,11 & 82,37 & 12 & 8 & 9 & 46,15 & 33,33 & 0 \\
\hline TEAM(2)vsTEAM(*) & 2 & 19,05 & 7,69 & 54,44 & 19 & 12 & 18 & 45,95 & 45,16 & 4 \\
\hline TEAM(1) vsTEAM(*) & 0 & 25,93 & 15,79 & 80,94 & 13 & 2 & 20 & 40,00 & 40,00 & 2 \\
\hline TEAM(12)vsTEAM(*) & 0 & 21,74 & 11,11 & 80,20 & 11 & 6 & 28 & 44,83 & 35,00 & 9 \\
\hline
\end{tabular}

\subsubsection{Factor analysis}

The second step of reduction is considered an application of a factor analysis. The factor analysis model specifies that variables are determined by common factors (the factors estimated by the model) and unique factors (which do not overlap between observed variables). The computed estimates are based on the assumption that all unique factors are uncorrelated with each other and with the common factors [16].

Having in mind that application of factor analysis imposes that it is applicable only in problems with big sampling (over 300 observations), feasibility test for factor analysis application will be carried out. There are two such tests in SPSS programme package (IBM Statistical Package for Social Scinces): Bartlett's test of sphericity and Kaiser-Meyer-Olkin (KMO) measures of sampling adequacy. Bartlett's test of sphericity should be important (for $p<0,005$ ), in order to make factor analysis feasible. KMO indicator can have value between 0 and 1 and therefore 0,6 is recommended as the smallest amount of original set of inputs.
Firstly, it will be checked whether the set of original inputs is adequate for factor analysis (Tab. 5). Having in mind that value of KMO indicators is equal to 0,602 , and that value of Bartlett's test of sphericity indicators is significant $(p=0,000)$, factor analysis is feasible.

Table 5 Measuring sample data adequacy for factor analysis

\begin{tabular}{|l|l|r|}
\hline \multicolumn{3}{|c|}{ KMO and Bartlett's Test } \\
\hline Kaiser-Meyer-Olkin Measure of Sampling Adequacy & 0,602 \\
\hline \multirow{3}{*}{ Bartlett's Test of Sphericity } & Approx. Chi-Square & 83,400 \\
\cline { 2 - 3 } & df & 36 \\
\cline { 2 - 3 } & Sig. & 0,000 \\
\hline
\end{tabular}

Pursuant to Kaiser criteria, only inputs with characteristic value 1 or more will be selected for analysis. Results shown in Tab. 6 will be needed to identify those components.

Header Initial Eigenvalues shows characteristic values of all components. Only the first three (crosses, crosses in play, passes in play) have characteristic values above $1(2,709 ; 1,856 ; 1,137)$. Those three components explain total of $63,352 \%$ of variance (see column Cumulative \%). 


\begin{tabular}{|c|c|c|c|c|c|c|c|c|c|}
\hline \multicolumn{3}{|c|}{ Communalities } & \multicolumn{7}{|c|}{ Total Variance Explained } \\
\hline \multirow{2}{*}{ Variables } & \multirow{2}{*}{ Initial } & \multirow{2}{*}{ Extraction } & \multirow{2}{*}{ Component } & \multicolumn{3}{|c|}{ Initial Eigenvalues } & \multicolumn{3}{|c|}{ Extraction Sums of Squared Loadings } \\
\hline & & & & Total & $\%$ of Variance & Cumulative \% & Total & $\%$ of Variance & Cumulative $\%$ \\
\hline$C$ & 1,000 & 0,812 & 1 & 2,709 & 30,104 & 30,104 & 2,709 & 30,104 & 30,104 \\
\hline$C P$ & 1,000 & 0,799 & 2 & 1,856 & 20,617 & 50,721 & 1,856 & 20,617 & 50,721 \\
\hline$P P$ & 1,000 & 0,496 & 3 & 1,137 & 12,631 & 63,352 & 1,137 & 12,631 & 63,352 \\
\hline$N S$ & 1,000 & 0,802 & 4 & 0,926 & 10,287 & 73,639 & & & \\
\hline$N S T$ & 1,000 & 0,822 & 5 & 0,788 & 8,754 & 82,394 & & & \\
\hline $\mathrm{NFm}$ & 1,000 & 0,428 & 6 & 0,677 & 7,518 & 89,911 & & & \\
\hline$A D$ & 1,000 & 0,448 & 7 & 0,507 & 5,635 & 95,546 & & & \\
\hline$G D$ & 1,000 & 0,535 & 8 & 0,211 & 2,343 & 97,890 & & & \\
\hline$N s D$ & 1,000 & 0,560 & 9 & 0,190 & 2,110 & 100,000 & & & \\
\hline
\end{tabular}

Having in mind that factor analysis is only a technique of data research, some "football suggestions" to interpretation of results has been added. Problem dimension allows us to add two more inputs. Isolated factors will be accompanied by: number of shots (NS) and number of shots in the target (NST), primarily because they represent elements of the game which are connected closer than any other with possible scores, that is, scored goals.

\subsection{DEA efficiency analysis}

In both cases, in offensive and defensive production, including analysis of technical efficiency under both aspects, the following DEA model of output orientation with variable productivity, can be applied [7]:

$(\max ) h_{k}=\sum_{r=1}^{s} \mu_{r} y_{r k}+u_{*}$,

subject to

$\sum_{i=1}^{m} v_{i} x_{i k}=1$,

$\sum_{r=1}^{s} \mu_{r} y_{r j}-\sum_{i=1}^{m} v_{i} x_{i j}-u_{*} \leq 0, j=1,2, \ldots, n$

$\mu_{r} \geq \varepsilon, r=1,2, \ldots, s$

$v_{i} \geq \varepsilon, i=1,2, \ldots, m$ where:

$h_{k}$ is relative efficiency score associated with $D M U_{k} ; x_{i j}$ is amount of input $i$ for $D M U_{j} ; y_{r j}$ is amount of output $r$ for $D M U_{j} ; n$ is number of $D M U s ; m$ is number of inputs; $s$ is number of outputs; $\mu_{r}$ is weight of output $r ; v_{i}$ is weight of input $i ; u_{*}$ is parameter that defines the position of the auxiliary hyperplane that lies at or above each DMU included in the analysis; $\varepsilon$ is small positive quantity $(\varepsilon=$ $\left.10^{-6}\right)$. The results of efficiency of offence of TEAM $(*)$ are given in Tab. 7, which contains the following elements:

DMU- decision making unit - name of a match in which TEAM(*) efficiency is observed; Score efficiency index - all DMUs having value $1(100 \%)$ are estimated as efficient units, because this refers to outputoriented model, and as we have already mentioned, value of virtual output is 1. In column Benchmarks legends for efficient and inefficient units are different. For efficient units, the number shows how many times one benchmark has been unit for inefficient entities; for inefficient units, ordinal number of a unit which is model to it is shown (or units if there is more of them) and appropriate vector of its influence intensity is shown in brackets. Slack $\{S\}$ are additional (slack) variables. Slack variables equal zero in efficient units. Obtained results represent offense by $\operatorname{TEAM}(*)$ as efficient at home in matches with $\operatorname{TEAM}(3)$, $\operatorname{TEAM}(4), \operatorname{TEAM}(7)$ and $\operatorname{TEAM}(8)$, while efficient offense, away, marks offenses realized by the national team in matches with $\operatorname{TEAM}(7), \operatorname{TEAM}(6), \operatorname{TEAM}(8)$, $\operatorname{TEAM}(10), \operatorname{TEAM}(2)$ and TEAM(12).

Table 7 Measuring offense efficiency

\begin{tabular}{|c|c|c|c|c|c|c|c|c|c|c|c|c|c|c|c|}
\hline & DMU & $\begin{array}{c}\text { Score } \\
\%\end{array}$ & $\begin{array}{c}C \\
\{I\} \\
\{V\}\end{array}$ & $\begin{array}{l}C P \\
\{I\} \\
\{V\}\end{array}$ & $\begin{array}{l}P P \\
\{I\} \\
\{V\}\end{array}$ & $\begin{array}{l}N S \\
\{I\} \\
\{V\}\end{array}$ & $\begin{array}{c}N S T \\
\{I\} \\
\{V\}\end{array}$ & $\begin{array}{l}N G \\
\{O\} \\
\{V\}\end{array}$ & $\mathrm{B}$ & $\begin{array}{c}S\} \\
C \\
\{I\}\end{array}$ & $\begin{array}{l}\{S\} \\
C P \\
\{I\}\end{array}$ & $\begin{array}{l}\{S\} \\
P P \\
\{I\}\end{array}$ & $\begin{array}{l}\{S\} \\
N S \\
\{I\}\end{array}$ & $\begin{array}{c}\{S\} \\
N S T \\
\{I\}\end{array}$ & $\begin{array}{l}\{S\} \\
N G \\
\{O\}\end{array}$ \\
\hline 1 & TEAM(*)vsTEAM(1) & 0,38 & 1,00 & 0,00 & 0,00 & 0,00 & 0,00 & 1,00 & $3(0,07) 12(0,93)$ & 0,00 & 0,54 & 26,35 & 10,15 & 5,44 & 0,00 \\
\hline 2 & $(*) \operatorname{vsTEAM}(2)$ & 0 & 0,00 & 1,00 & 0,00 & 0,00 & 0,00 & 1,00 & $8(0,04) 12(0,96)$ & 0,52 & 0,00 & 18,60 & 5,24 & 2,76 & 0,00 \\
\hline 3 & 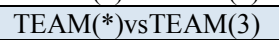 & 0,00 & 0,00 & 0,00 & 0,00 & 1,00 & 0,00 & 1,00 & & & & & & & \\
\hline 4 & TEAM(*)vsTEAM(4) & 00,00 & 1,00 & 0,00 & 0,00 & 0,00 & 0,00 & 1,00 & & & & & & & \\
\hline 5 & TEAM(*)vsTEAM(5) & 43,64 & 1,00 & 0,00 & 0,00 & 0,00 & 0,00 & 1,00 & $3(0,10) 12(0,90)$ & 0,00 & 11,25 & 14,39 & 3,76 & 1,18 & 0,00 \\
\hline 6 & TEAM(*)vsTEAM(6) & 7,50 & 0,00 & 0,00 & 0,00 & 0,00 & 1,00 & 1,00 & $3(0,25) 12(0,75)$ & 8,26 & 6,77 & 9,07 & 1,00 & 0,00 & 0,00 \\
\hline 7 & TEAM(*)vsTEAM(7) & 100,00 & 0,23 & 0,59 & 0,00 & 0,00 & 0,18 & 1,00 & & & & & & & \\
\hline 8 & *)VsTFAM(8) & 100,00 & 0,00 & 1,00 & 0,00 & 0,00 & 0,00 & 1,00 & & & & & & & \\
\hline 9 & $T$ & 0,00 & 0,00 & 1,00 & 0,00 & 0,00 & 1,00 & 1,00 & & & & & & & \\
\hline 10 & TEAI & 0,00 & 0,11 & 1,00 & 0,00 & 0,78 & 0,00 & 1,00 & & & & & & & \\
\hline 11 & TEAM(9)vsTEAM(*) & 3,33 & 0,00 & 0,00 & 0,00 & 0,00 & 1,00 & 1,00 & $3(0,50) 12(0,50)$ & 4,45 & 7,99 & 7,67 & 3,00 & 0,00 & 0,00 \\
\hline 12 & TEAM(8)vsTEAM $(*)$ & 0,00 & 0,03 & 0,08 & 0,81 & 0,08 & 0,00 & 1,00 & & & & & & & \\
\hline 13 & TEAM(1)vsTEAM $(*)$ & 135,26 & 1,00 & 0,00 & 0,00 & 0,00 & 0,00 & 1,00 & $3(0,02) 12(0,98)$ & 0,00 & 4,19 & 26,94 & 12,77 & 6,85 & 0,00 \\
\hline 14 & TEAM(10)vsTEAM(*) & 100,00 & 0,03 & 0,00 & 0,34 & 0,64 & 0,00 & 1,00 & & & & & & & \\
\hline 15 & TEAM(2)vsTEAM $(*)$ & 100,00 & 0,00 & 0,00 & 1,00 & 0,00 & 0,00 & 1,00 & & & & & & & \\
\hline 16 & TEAM(11)vsTEAM(*) & 224,21 & 0,00 & 1,00 & 0,00 & 0,00 & 0,00 & 1,00 & ,76) & 5,09 & 0,00 & 19,74 & 5,40 & 1,55 & 0,00 \\
\hline 17 & TEAM(12)vsTEAM(*) & 100,00 & 0,00 & 0,75 & 0,00 & 0,25 & 0,00 & 1,00 & & & & & & & \\
\hline
\end{tabular}


Output-oriented model seeks to maximize output with given quantity of inputs, and therefore inefficient units, with index higher than $1(100 \%)$, are published bottomup. For each inefficient match benchmark can be designated at efficiency limit. For match 1 (DMU1), namely TEAM(*)vsTEAM(1), it is hypothetical unit which occurs as linear combination of inputs and output of offensive game in matches 3 (DMU3): TEAM $(*)$ vs TEAM(3) and 12 (DMU12): TEAM(8)vsTEAM(*), since hypothetical unit is located in line which connects these two DMUs. Index of efficiency can be also calculated as relation of radial distance of its benchmark from the origin of coordinates. Value of quotient represents index of efficiency for DMU1 and it states how much, in percentages, one unit needs to increase output in order to become efficient. In case of match 1 (DMU1), output should be increased 1,4 times, that is, in case a number of scored goals is approximately equal to 4, DMU1 would be placed near hypothetical point at efficiency limit.

In Tab. 8, matches with inefficient offensive activities are shown, with real input and output and desired (targeted) input and output which would provide efficiency. Desired input values are generated as difference between the real and equalising values, while desired value of output is obtained as product of real value and efficiency index reduced for equalising variable.

Table 8 Real and desired values of inputs and output of inefficient DMU - offense analysis

\begin{tabular}{|c|c|c|c|c|c|c|}
\hline Match (DMU) & $C$ & $C P$ & $P P$ & $N S$ & $N S T$ & $N G$ \\
\hline TEAM(*)vsTEAM(1) & $19,61(19,61)$ & $20,00(19,46)$ & $90,46(64,11)$ & $19(9)$ & $9(4)$ & $2(3)$ \\
\hline TEAM(*)vsTEAM(2) & $29,03(18,51)$ & $17,39(17,39)$ & $81,91(63,31)$ & $14(9)$ & $6(3)$ & $3(3)$ \\
\hline TEAM(*)vsTEAM(5) & $20,51(20,51)$ & $32,00(20,75)$ & $79,17(64,78)$ & $13(9)$ & $5(4)$ & $2(3)$ \\
\hline TEAM(*)vsTEAM(6) & $42,86(24,60)$ & $33,33(26,56)$ & $76,90(67,83)$ & $12(11)$ & $5(5)$ & $1(4)$ \\
\hline TEAM(9)vsTEAM(*) & $36,00(31,55)$ & $44,44(36,45)$ & $80,68(73,01)$ & $17(14)$ & $7(7)$ & $2(4)$ \\
\hline TEAM(1)vsTEAM(*) & $18,18(18,18)$ & $21,62(17,43)$ & $89,98(63,04)$ & $21(8)$ & $10(3)$ & $2(3)$ \\
\hline TEAM(11)vsTEAM $(*)$ & $28,00(22,91)$ & $21,05(21,05)$ & $86,42(66,68)$ & $18(13)$ & $6(4)$ & $1(3)$ \\
\hline
\end{tabular}

Table 9 Measuring defence efficiency

\begin{tabular}{|c|c|c|c|c|c|c|c|c|c|c|c|c|c|c|c|}
\hline & DMU & $\begin{array}{c}\text { Score } \\
\%\end{array}$ & \begin{tabular}{|c|}
$C$ \\
$\{I\}$ \\
$\{V\}$ \\
\end{tabular} & \begin{tabular}{|l|}
$C P$ \\
$\{I\}$ \\
$\{V\}$ \\
\end{tabular} & \begin{tabular}{|l|}
$P P$ \\
$\{I\}$ \\
$\{V\}$ \\
\end{tabular} & \begin{tabular}{|l|}
$N S$ \\
$\{I\}$ \\
$\{V\}$ \\
\end{tabular} & $\begin{array}{c}N S T \\
\{I\} \\
\{V\} \\
\end{array}$ & $\begin{array}{l}N G \\
\{O\} \\
\{V\} \\
\end{array}$ & Benchmarks & $\begin{array}{c}\{S\} \\
C \\
\{I\} \\
\end{array}$ & $\begin{array}{l}\{S\} \\
C P \\
\{I\}\end{array}$ & $\begin{array}{l}\{S\} \\
P P \\
\{I\}\end{array}$ & $\begin{array}{l}\{S\} \\
N S \\
\{I\} \\
\end{array}$ & $\begin{array}{c}\{S\} \\
N S T \\
\{I\}\end{array}$ & $\begin{array}{l}\{S\} \\
N G \\
\{O\}\end{array}$ \\
\hline 1 & TEAM(*)vsTEAM(2) & 100,00 & 0,00 & 0,29 & 0,44 & 0,22 & 0,04 & 1,00 & 6 & & & & & & \\
\hline 2 & TEAM(*)vsTEAM(3) & 200,00 & 0,46 & 0,21 & 0,15 & 0,14 & 0,04 & 1,00 & $1(0,54) 4(0,04) 5(0,08) 7(0,04) 10$ & 5,96 & 3,04 & 5,60 & 7,99 & 7,37 & 0,00 \\
\hline 3 & TEAM(*)vsTEAM(4) & 100,00 & 0,19 & 0,00 & 0,68 & 0,12 & 0,00 & 1,00 & 0 & & & & & & \\
\hline 4 & TEAM(*)vsTEAM(5) & 100,00 & 0,12 & 0,00 & 0,88 & 0,00 & 0,00 & 1,00 & 4 & & & & & & \\
\hline 5 & TEAM(*)vsTEAM(6) & 100,00 & 0,06 & 0,00 & 0,89 & 0,00 & 0,06 & 1,00 & 4 & & & & & & \\
\hline 6 & TEAM(*)vsTEAM(7) & 100,00 & 0,65 & 0,35 & 0,00 & 0,00 & 0,00 & 1,00 & 0 & & & & & & \\
\hline 7 & TEAM $(*)$ vsTEAM $(8)$ & 100,00 & 0,00 & 0,00 & 0,00 & 0,00 & 1,00 & 1,00 & 4 & & & & & & \\
\hline 8 & TEAM(7)vsTEAM(*) & 300,30 & 0,61 & 0,11 & 0,23 & 0,02 & 0,03 & 1,00 & $1(0,36) 4(0,09) 5(0,12) 7(0,08) 10$ & 7,01 & 15,30 & 10,14 & 12,19 & 7,40 & 0,00 \\
\hline 9 & TEAM(6)vsTEAM(*) & 100,00 & 0,59 & 0,00 & 0,00 & 0,00 & 0,41 & 1,00 & 0 & & & & & & \\
\hline 10 & TEAM(9)vsTEAM(*) & 100,00 & 0,00 & 0,00 & 0,67 & 0,32 & 0,00 & 1,00 & 3 & 5,03 & 3,44 & 0,02 & 0,03 & 1,38 & 0,00 \\
\hline 11 & TEAM(8)vsTEAM(*) & 291,57 & 0,00 & 0,00 & 1,00 & 0,00 & 0,00 & 1,00 & $12(0,96) 14(0,04)$ & 4,67 & 1,12 & 0,00 & 4,56 & 0,61 & 0,00 \\
\hline 12 & TEAM(1)vsTEAM(*) & 100,00 & 0,00 & 0,00 & 0,87 & 0,07 & 0,06 & 1,00 & 5 & & & & & & \\
\hline 13 & TEAM(10)vsTEAM(*) & 200,00 & 0,00 & 1,00 & 0,00 & 0,00 & 0,00 & 1,00 & $1(0,89) 16(0,11)$ & 1,87 & 0,00 & 3,04 & 3,71 & 5,55 & 0,00 \\
\hline 14 & TEAM(2)vsTEAM(*) & 100,00 & 0,00 & 0,03 & 0,97 & 0,00 & 0,00 & 1,00 & 1 & & & & & & \\
\hline 15 & TEAM(11)vsTEAM(*) & 100,00 & 0,05 & 0,59 & 0,18 & 0,02 & 0,15 & 1,00 & $1(0,75) 4(0,02) 5(0,05) 7(0,12) 10$ & 6,29 & 0,55 & 3,04 & 3,71 & 0,01 & 0,00 \\
\hline 16 & TEAM(12)vsTEAM $(*)$ & 100,00 & 0,00 & 1,00 & 0,00 & 0,00 & 0,00 & 1,00 & $1(1,00)$ & 5,74 & 0,00 & 1,68 & 3,00 & 4,00 & 0,00 \\
\hline
\end{tabular}

In the same category of DEA model, reciprocal values of received goals has been used for output, in order to observe defence efficiency of $\operatorname{TEAM}(*)$ through opponents' offense inefficiency.

Tab. 9 represents results of defense efficiency. It is interesting to notice two DMUs: TEAM(11)vsTEAM $(*)$ and TEAM(12)vsTEAM $(*)$ with efficiency index $1(100 \%)$, but declared as inefficient. It is possible to see in charts that they are located on interrupted segments of efficiency limit which are parallel to abscissa or ordinate. Model for defence in match with $\operatorname{TEAM}(12)$ was defence in duel with $\operatorname{TEAM}(2)$, at home, while for defence in match with TEAM(11) model unit was represented as hypothetical point generated by linear combination of the game in matches with $\operatorname{TEAM}(2)$, $\operatorname{TEAM}(5), \operatorname{TEAM}(6)$ and $\operatorname{TEAM}(8)$ at home and with $\operatorname{TEAM}(9)$ away, with influence intensity vectors 0,75 ; 0,$02 ; 0,05 ; 0,12 ; 0,06$. In both cases, values of equalising variables, higher than zero, indicate their inefficiency.

Tab. 10 presents matches with inefficient defence activities of TEAM(*), with real inputs and outputs, and desired (targeted) inputs and outputs which would provide efficiency. Desired values of outputs are generated in compliance with transformations carried out in order to be adjusted to the model.

\subsection{Two-stage DEA}

Despite the access to the same technical level (planning, physical training, tactics,...), national teams including football teams - are obviously different when it comes to the level of their efficiency, which implies and explains differences in their productivity. With reference to previously obtained and presented results objective of this part of the paper is not to repeat analysis of technical and tactical parameters of the game, but analysis of the second phase in DEA approach which, with application of previous information on efficiency of TEAM $(*)$ offense and defence, in a form of newly identified input values, in relation with number of scored goals of TEAM $(*)$ in total 
Number of opponent's received goals (TG), including goal difference achieved by TEAM (*) in each game (GD), and preserving the nature of DEA model, should give a new overview of TEAM $(*)$ efficiency analysis.

Modelling shall be carried out on sample of 10 qualification games, while values of offense and defence efficiency, generated pursuant to technical and tactical elements, including friendly games, due to overview TEAM(*) total "level" in all games during "qualification" period.

Table 10 Real and desired values of inputs and outputs of inefficient DMU - defence analysis

\begin{tabular}{|c|c|c|c|c|c|c|}
\hline Match $(D M U)$ & $C$ & $C P$ & $P P$ & $N S$ & $N S T$ & $N G$ \\
\hline TEAM $(*)$ vsTEAM $(3)$ & $26,09(20,13)$ & $18,75(15,71)$ & $83,82(78,22)$ & $18(10)$ & $10(3)$ & $1(0)$ \\
\hline TEAM(7)vsTEAM $(*)$ & $29,17(22,16)$ & $35,29(19,99)$ & $87,48(77,34)$ & $23(11)$ & $10(3)$ & $2(0)$ \\
\hline TEAM(8)vsTEAM $(*)$ & $29,41(24,74)$ & $33,33(32,21)$ & $73,35(73,35)$ & $14(10)$ & $4(3)$ & $2(0)$ \\
\hline TEAM(10)vsTEAM $(*)$ & $18,52(16,65)$ & $11,11(11,11)$ & $82,37(78,71)$ & $12(8)$ & $8(2)$ & $1(0)$ \\
\hline TEAM(11)vsTEAM $\left(^{*}\right)$ & $25,93(19,64)$ & $15,79(15,24)$ & $80,94(77,90)$ & $13(9)$ & $2(2)$ & $0(0)$ \\
\hline TEAM(12)vsTEAM $(*)$ & $21,74(16,00)$ & $11,11(11,11)$ & $80,20(78,52)$ & $11(8)$ & $6(2)$ & $0(0)$ \\
\hline
\end{tabular}

Having in mind that output-oriented model was also used in the previous analysis, obtained indexes of efficacy represented as input in new observation, will be prepared in their reciprocal values, due to nature of influence on efficacy phenomenon considered in this model. Also, due to data negativity condition, output which represents goal difference was modified by simple transformation [7].

Results obtained by EMS software are presented in Fig. 11. The column "Score" indicates that the matches $\operatorname{TEAM}(*)$ played with $\operatorname{TEAM}(2), \operatorname{TEAM}(6)$ and $\operatorname{TEAM}(8)$, as well as $\operatorname{TEAM}(7)$ and $\operatorname{TEAM}(8)$ at home, are still considered efficient matches. Although the independent analyses of the matches with TEAM (6) and TEAM (2) are declared to be efficient, the results of the new analysis have shown that the matches identified as inefficient with efficiency indices of 1,385 and 3,047 . If the desired output level were $1,385(3,047)$ times greater (minus slack variable), the efficiency of TEAM $\left(^{*}\right)$ could be expected at these matches. The similar analysis can be conducted and compared to the other matches considered in Fig. 11.

Table 11 Measuring offence and defence efficiency in the second-staged DEA

\begin{tabular}{|c|c|c|c|c|c|c|c|c|c|c|c|}
\hline & DMU & $\begin{array}{c}\text { Score } \\
\%\end{array}$ & $\begin{array}{l}\text { E. Offence } \\
\quad\{I\}\{V\}\end{array}$ & $\begin{array}{l}\text { E. Defence } \\
\{I\}\{V\}\end{array}$ & $\begin{array}{l}T T \\
\{I\} \\
\{V\}\end{array}$ & $\begin{array}{l}G D \\
\{I\} \\
\{V\}\end{array}$ & Benchmarks & $\begin{array}{c}\{S\} \\
\text { E. Offence } \\
\{I\}\end{array}$ & $\begin{array}{c}\{S\} \\
\text { E. Defence } \\
\{I\}\end{array}$ & $\begin{array}{l}\{S\} \\
T G \\
\{I\}\end{array}$ & $\begin{array}{l}\{S\} \\
G D \\
\{I\}\end{array}$ \\
\hline 1 & TEAM(*)vsTEAM(1) & 125,31 & 0,62 & 0,38 & 0,00 & 1,00 & $3(0,50) 5(0,50)$ & 0,00 & 0,00 & 0,05 & 0,00 \\
\hline 2 & TEAM(*)vsTEAM(2) & 100,00 & 0,80 & 0,20 & 1,00 & 0,00 & 0 & & & & \\
\hline 3 & TEAM(*)vsTEAM(6) & 100,00 & 0,50 & 0,50 & 0,91 & 0,09 & 2 & & & & \\
\hline 4 & TEAM(*)vsTEAM(7) & 249,32 & 0,47 & 0,53 & 1,00 & 0,00 & $5(1,00)$ & 0,00 & 0,00 & 0,00 & 2,01 \\
\hline 5 & TEAM(*)vsTEAM(8) & 100,00 & 0,00 & 1,00 & 0,00 & 1,00 & 5 & & & & \\
\hline 6 & TEAM(7)vsTEAM(*) & 100,00 & 0,12 & 0,88 & 0,99 & 0,01 & 0 & & & & \\
\hline 7 & TEAM(6)vsTEAM(*) & 138,50 & 0,47 & 0,53 & 1,00 & 0,00 & $5(1,00)$ & 0,00 & 0,00 & 0,00 & 0,07 \\
\hline 8 & TEAM(8)vsTEAM(*) & 100,00 & 0,41 & 0,59 & 0,00 & 1,00 & 0 & & & & \\
\hline 9 & TEAM(1)vsTEAM(*) & 129,97 & 0,62 & 0,38 & 0,00 & 1,00 & $3(0,45) 5(0,55)$ & 0,00 & 0,00 & 0,05 & 0,00 \\
\hline 10 & TEAM(2)vsTEAM(*) & 304,73 & 0,26 & 0,74 & 1,00 & 0,00 & $5(1,00)$ & 0,00 & 0,00 & 0,00 & 3,95 \\
\hline
\end{tabular}

\section{Conclusion}

Isolating of tactical and technical elements in football game, given in numeric form as evaluation of TEAM(*) players' activity in the field (or in case of defence: through impossibility to prevent identical movements and activities of opponent) has contributed to creation of prerequisites for application of DEA model in efficacy analysis of individual or, as in this case, the whole circle of football events. Integral consideration of TEAM(*) efficiency in qualification tournament for the biggest football competition of national selections, taking in account previously obtained efficiency indexes in form of input values, in two contexts of achieved result set as outputs $(T G, G D)$.

Taking results into consideration, it can be decidedly concluded that efficiency of total play has been changed, i.e. the presented play and achieved result of TEAM $(*)$ has undergone transformation in integral model. Games where $\operatorname{TEAM}(*)$ was efficient with regards to both aspects, but separately, by putting together results from the previous analysis, became "inefficient" and vice versa.

Different decompositions of problems and difference in start-up strategies at selecting research direction indicate the fact that complex process of modelling exact situations represents to authors both great challenge and in exhaustible resource of inspiration and further work, despite all difficulties.

\section{$5 \quad$ References}

[1] Rottenberg, S. The baseball player's labor-market. // Journal of Political Economy. 64(1956), pp. 242-258. DOl: $10.1086 / 257790$

[2] Scully, G. W. Pay and performance in major league baseball. // American Economic Review. 64(1974), pp. 915-930.

[3] Zak, T. A.; Huang C. J.; Siegfried, J. J. Production efficiency: the case of professional basketball. // Journal of Business. 52(1979), pp. 379-392. DOI: 10.1086/296053

[4] Scott, F. A.; Long, J. E.; Somppi, K. Salary vs marginal revenue product under monopsony and competition: the case of professional basketball. // Atlantic Economic Journal. 13(1985), pp. 50-59. DOI: 10.1007/BF02304294

[5] Carmichael, F.; Thomas, D. Production and efficiency in team sports: an investigation of rugby league football. // Applied Economics. 27(1995), pp. 859-869. DOl: $10.1080 / 00036849500000039$

[6] Carmichael, F.; Thomas, D.; Ward, R. Team performance: the case of English premiership football. // Managerial and 
Decision Economics. 21(2000), pp. 31-45. DOI: 10.1002/1099-1468(200001/02)21:1<31::AID-MDE963>3.0.CO;2Q

[7] Cooper, W. W.; Seiford, L. M.; Tone, K. Data Envelopment Analysis: A Comprehensive Text with Models, Applications, References and DEA-Solver Software. $2^{\text {nd }}$ ed. Springer, 2007.

[8] Haas, D. J.; Kocher, M. G.; Sutter, M. Measuring efficiency of German football teams by data envelopment analysis. // Central European Journal of Operations Research. 12(2004), pp. 251-268.

[9] Hass, D. J. Technical efficiency in the major league soccer. // Journal of Sports Economics. 4(2003), pp. 203-215. DOl: 10.1177/1527002503252144

[10] Garcia-Sanchez, I. M. Efficiency and effectiveness of Spanish football teams: A three-stage-DEA approach. // Central European Journal of Operations Research. 15(2007), pp. 21-45. DOI: 10.1007/s10100-006-0017-4

[11] Bosca, J. E.; Liem, V.; Martinez, A.; Sala, R. Increasing offensive or defensive efficiency: An analysis of Italian and Spanish football. // Omega. 37(2009), pp. 63-78. DOI: 10.1016/j.omega.2006.08.002

[12] Sala-Garido, R.; Carrion V. L.; Esteve, A. M.; Bosca, J. E. Analysis and evolution of efficiency in the Spanish soccer league (2000/01-2007/08). // Journal of Quantitative Analysis in Sports. 5(2009), pp. 1-22. DOI: 10.2202/1559-0410.1143

[13] Neale, W. C. The peculiar economics of professional sports: A contribution to the theory of the firm sporting competition and in market competition. // The Quarterly Journal of Economics. 78(1964), pp. 1-14. DOl: $10.2307 / 1880543$

[14] Sexton, T. R.; Lewis, H. F. Two-stage DEA: An application to major league baseball. // Journal of Productivity Analysis. 19(2003), pp. 227-249. DOl: 10.1023/A:1022861618317

[15] Banker, R. D.; Charnes, A.; Cooper, W. W. Some models for estimating technical and scale inefficiencies in data envelopment analysis. // Management Science. 30(1984), pp. 1078-1092. DOI: $10.1287 / \mathrm{mnsc} .30 .9 .1078$

[16] SPSS Base 13.0 User's Guide, SPSS Inc., USA, 2004.

\section{Authors' addresses}

Dijana Petrović Djordjević, PhD candidate

Faculty of Organizational Sciences, University of Belgrade 154, Jove Ilića St. 11000 Belgrade, Serbia

E-mail: dijana.petrovic@fss.rs

\section{Mirko Vujošević, Full professor}

Faculty of Organizational Sciences, University of Belgrade 154, Jove Ilića St. 11000 Belgrade, Serbia

E-mail: vujosevic.mirko@fon.bg.ac.rs

\section{Milan Martić, Full professor}

Faculty of Organizational Sciences, University of Belgrade 154, Jove Ilića St. 11000 Belgrade, Serbia

E-mail: martic.milan@fon.bg.ac.rs 